\title{
CAPTURE
}

\section{SOEGIJA BIOPIC FILM, POLITICAL AFIRMATION, AND POLITICAL IDENTITY: DECONSTRUCTION OF INDONESIAN HISTORIOGRAPHY}

\author{
Bambang Aris Kartika', Nanik Sri Prihatini ${ }^{2}$, Sri Hastanto ${ }^{3}$, dan Dharsono ${ }^{4}$ \\ 1 Universitas Jember, Jawa Timur, Indonesia \\ 2 Institut Seni Indonesia (ISI) Surakarta, Jawa Tengah, Indonesia \\ 3 Institut Seni Indonesia (ISI) Surakarta, Jawa Tengah, Indonesia \\ ${ }^{4}$ Institut Seni Indonesia (ISI) Surakarta, Jawa Tengah, Indonesia \\ E-mail: bamsliverpudlian@gmail.com
}

\begin{abstract}
Soegija's movie is a biopic film based on the historiography of the highest leaders of the people and the Catholic church in Indonesia. Soegija's film is an antithesis of Indonesian historiography so far, especially the historiography of the era of the Indonesian independence revolution. This article discusses the political affirmation and identity politics of Soegija's film from the perspective of Derrida's Deconstruction. Derrida's Deconstruction approach and historical methodology consisting of Heuristics, Hermeneutics, and internal criticism are used to understand the position of Soegija's biopic on Indonesian historiography. The results of the study show that Soegija's film is a biography moving picture of the character Mgr. Albertus Soegijapranata, who narrated historical facts about the national attitude of the Catholic leadership as the first native bishop. In deconstruction, it appears that Soegija's biopic is a representation of the political affirmation and identity politics of educational cultural resistance to the truth of the historical facts of the character Mgr. Albertus Soegijapranata who is in binary opposition to Indonesian historiography.
\end{abstract}

Keywords: Affirmation, identity, deconstruction, historiography, and biopic films

\section{ABSTRAK}

Film Soegija sebagai film biopik berdasarkan pada historiografi dari tokoh pemimpin tertinggi umat dan gereja Katolik di Indonesia. Film Soegija merupakan satu antithesis terhadap historiografi Indonesia selama ini, khususnya historiografi pada era revolusi kemerdekaan Indonesia. Artikel ini membahas tentang afirmasi politik dan politik identitas pada film Soegija dari perspektif Dekonstruksi Derrida. Pendekatan Dekonstruksi Derrida dan metodologi sejarah yang terdiri atas Heuristik, Hermeneutik, dan kritik internal dipakai untuk memahami posisi film biopik Soegija terhadap historiografi Indonesia. Hasil kajian menunjukkan film Soegija merupakan film biografi atau biopic (biography moving picture) dari tokoh Mgr. Albertus Soegijapranata yang menarasikan fakta-fakta historis tentang sikap kebangsaan dari pimpinan umat Katolik sebagai uskup pribumi pertama. Secara dekonstruksi tampak bahwa film biopik Soegija merupakan representasi dari afirmasi politik dan politik identitas perlawanan kultural edukatif atas kebenaran fakta sejarah biografi tokoh Mgr. Albertus Soegijapranata yang beroposisi biner dengan historiografi Indonesia.

Kata kunci: Afirmasi, identitas, dekonstruksi, historiografi, dan film biopik

\section{PENDAHULUAN}

Perkembangan sub genre film biopik di industri film Indonesia periode tahun 2000-an ditandai oleh kesuksesan film Sang Pencerah karya sutradara Hanung Bramantyo yang seiring dengan lakunya 
film-film dari adaptasi novel religi. Era tersebut tampak film-film adaptasi dari novel religi telah membentuk lanskap industri perfilman Indonesia, khususnya film-film dengan identitas keislaman, artinya identitas keislaman sangat mewarnai film-film yang mengakomodasi pasar Islami di Indonesia. Faktanya memang secara marketability cukup sukses mendulang ceruk keuntungan dari pasar film Indonesia, seperti film Ayat-Ayat Cinta (AAC), Ketika Cinta Bertasbih (KCB), Ketika Cinta Bertasbih 2 (KCB2), dan Perempuan Berkalung Sorban (PBS). Filmfilm tersebut terbukti cukup sukses diterima oleh pasar penonton film di Indonesia. Film Ayat-Ayat Cinta (2008) memperoleh jumlah penonton mencapai 3.675 .35 , film Ketika Cinta Bertasbih (2009) mendulang jumlah penonton hingga 2.105.192, film Ketika Cinta Bertasbih 2 mendapat penonton sebesar 1.494.739, dan film Perempuan Berkalung Sorban (2009) mendulang penonton hingga mencapai sejumlah 793.277 (www.filmindonesia.or.id). Trend film berbasis religi dan adanya pasar Islami ini diakui oleh Hanung Bramantyo sebagai salah satu pertimbangan memproduksi film Sang Pencerah. Hanung Bramantyo menyatakan, "Setelah Ayat-Ayat Cinta ide membuat film Sang Pencerah muncul lagi ternyata ada 'pasar Islami' di Indonesia. Saya melihat pasaran itu dari Ayat-Ayat Cinta," (Pratama, 2010).

Film Sang Pencerah mampu memperolehan penonton hingga mencapai 1,2 juta menunjukkan bahwa film sejarah secara marketability (pasar) dan playability (penerimaan penonton) memiliki segmentasi pasar sebagai produk komoditas media, sebagaimana yang dikemukakan oleh (Keerigan, 2010) bahwa pertimbangan memproduksi film yang dihasilkan berdasar atas dua pertimbangan, yaitu: marketability dan playability. Marketability merupakan peluang film diterima oleh pasar yang besar (mass market). Film adaptasi dari novel merupakan salah satu faktor marketability dalam produksi film. Playability adalah bagaimana film yang diproduksi akan diterima oleh penontonnya.

Pasca booming film Sang Pencerah, industri perfilman Indonesia diwarnai oleh hadirnya film biopik karya sutradara Garin Nugroho, yaitu film Soegija. Film sejarah uskup pribumi pertama Indonesia sekaligus pahlawan nasional dari golongan minoritas umat Katolik. Film ini dalam konteks industri perfilman ketika itu menjadi satu anomali di tengah booming film-film berbasis novel religi dan pasar Islami. Garin Nugroho dikenal gemar mengangkat tema-tema yang sensitif di mata publik, salah satunya adalah isu-isu minoritas. "Saya selalu mengambil tema-tema sensitif yang belum ada saja. Lalu memang pemimpin minoritas jarang diekspose" (Wawancara Garin Nugroho, 28 Februari 2020). Garin Nugroho secara idealis berani 
mendekonstruksi film-film mainstream yang berorientasi pada aspek komersial. Konsekuensi dari keberanian sekaligus keberpihakan Garin Nugroho memproduksi film-film yang berkelindan dengan isu-isu minoritas mengakibatkan efek bahwa terkadang menimbulkan kontroversial di tengah publik seperti penolakan dari kelompok-kelompok yang tidak sepaham dengan film karya kreatifnya.

Film Soegija sebagai film biopik berdasarkan pada historiografi dari tokoh pemimpin tertinggi umat dan gereja Katolik di Indonesia, memiliki unsur-unsur kepentingan secara politik. Film dokudrama biopik merekonstruksi adegan masa lalu berdasarkan tafsirannya (Ayawaila, 2008). SAV Puskat yang memproduksi film Soegija memiliki penafsiran tentang pentingnya sosok Uskup Mgr. Albertus Soegijapranata dihadirkan di tengah dinamisasi komersialiasi industri perfilman Indonesia. Peran rohaniawan Katolik terkait dengan sejarah masa-masa revolusi fisik kemerdekaan Indonesia terlupakan, bahkan teralienasi dalam penulisan sejarah (historiografi) Indonesia. Konsep 100\% Katolik 100\% Indonesia dan dukungan politik atas pengakuan pertama kali kedaulatan Republik Indonesia oleh Tahta Suci Vatikan atas andil besar dari Mgr. Albertus Soegijapranata juga baru dikenalkan publik melalui catatan harian Romo Soegija yang diterbitkan menjadi buku pada masa pasca Orde Baru.
Bahkan, penulisan sejarah masa Orde Baru, sarat dengan peran heroik dari tokohtokoh sipil nasionalis ataupun militer dibandingkan tokoh agama, apalagi agama Katolik. Kalaupun ada, kebanyakan film yang diproduksi dalam film-film sejarah berasal dari kalangan ulama-ulama beragama Islam. Sebagian besar penulisan sejarah (historiografi) mengagungkan peran militer dalam konteks meraih kemerdekaan, seperti sejarah besar Soekarno-Hatta-Sjahrir, Panglima Besar Jenderal Soedirman, Jenderal Soeharto (mantan Presiden Kedua Republik Indonesia), ataupun tokoh-tokoh sipil nasionalis lainnya.

Penulisan sejarah (historiografi) pada realitasnya seringkali melakukan manipulasi terhadap peran para tokohtokoh besar (the great men) dalam peristiwa besar dalam sejarah, termasuk historiografi Indonesia. Manipulasi penulisan sejarah (historiografi) seringkali dilakukan oleh rezim otoritarian yang berkuasa sebagai bentuk aktualisasi hegemoni politik untuk tujuan melanggengkan kekuasaan. Sejarah dijadikan sebagai dasar legitimasi atas hegemoni politik kekuasaan suatu rezim. Penulisan sejarah seakan-akan difungsikan sebagai afirmasi politik bagi rezim untuk menghegemoni kekuasaan politik. Rommel Curaming (dalam Palmos, 2016) bahwa penulisan sejarah sangat sering dipelintir untuk kepentingan tertentu. (Palmos, 2016) 
mencontohkan gaya Presiden Soekarno (1945-1966) dan Soeharto (1966-1998) dalam menggunakan pendekatan yang sama terhadap sejarah kemerdekaan, yaitu dengan menata ulang penulisannya sebagai propaganda bagi rezim mereka masing-masing. Fakta ini merupakan sebuah hal yang banyak terjadi dalam sejarah dunia. Bahkan, hingga tahun-tahun terakhir pemerintahan Presiden Soeharto, pemerintah Orde Baru masih berusaha untuk mengendalikan penulisan sejarah Indonesia, dengan tujuan utama untuk menonjolkan peran Soeharto sekaligus menempatkan $\mathrm{ABRI} / \mathrm{TNI}$ di garda terdepan Revolusi Kemerdekaan (Palmos, 2016).

Ruang ilmiah harus terbebas dari manipulasi politik terhadap penulisan sejarah menjadi hal yang sangat penting bagi independensi riset-riset akademik kritis, termasuk pada kajian film tentang sejarah. Apalagi kemampuan film untuk membangun kesadaran publik sangat efektif untuk melakukan indoktrinasi ideologi tentang pengakuan atas fakta kebenaran sejarah penguasa, selain melalui penulisan teks-teks historiografi. Film Soegija merupakan satu antithesis terhadap historiografi Indonesia selama ini, khususnya historiografi pada era revolusi kemerdekaan. Bagaimana kalangan rohaniawan Katolik juga berkontribusi terhadap sejarah pembentukan Negara Kesatuan Republik Indonesia, tidak saja dari kalangan ulama-ulama Islam, seperti
K.H. Hasyim Asy'ari melalui Resolusi Jihad maupun peran tokoh-tokoh militer dan sipil, seperti Jenderal Soedirman, Jenderal Soeharto, Bung Tomo, Soekarno, Hatta, Sjahrir, ataupun Sri Sultan Hamengkubuwono IX. Film tidak hanya dipandang menjadi media tontonan yang menghibur, melainkan juga berfungsi sebagai media ekspresi yang sarat dengan nilai-nilai estetis, etika, moral, dan ideologi (Palmos, 2016).

Berdasarkan deskripsi latar belakang masalah di atas, maka tujuan dari penulisan artikel ini adalah (1) untuk mengungkapkan dan mendeskripsikan tujuan utama (the main purpose) produksi film Soegija dari perspektif historiografi Indonesia, dan (2) mengidentifikasikan faktor-faktor yang melatarbelakangi kepentingan diproduksinya film Soegija. Harapan dari proses ini adalah akan ditemukan posisioning film Soegija terhadap historiografi revolusi kemerdekaan Indonesia. Film biopik meskipun karya fiksi, akan tetapi tidak bisa meninggalkan kepentingan-kepentingan tersembunyi di balik di produksinya sebagai media tontonan kepada publik.

Film bisa menjalankan fungsi kritis terhadap kebenaran sejarah. Film Soegija dapat dimaknai sebagai upaya kultural edukatif dengan mendekonstruksi historigrafi Indonesia. Bahkan, film Soegija merupakan artikulasi pengakuan atas afirmasi sejarah yang sangat strategis 


\section{CAPTURE}

sebagai mesin perjuangan politik bagi golongan minoritas. Afirmasi politik sebagai aktualisasi dari perlawanan kultural edukatif melalui media karya seni audiovisual yang direpresentasikan dengan teks-teks sinema dari pengaruh alienasi dan marginalisasi peran rohaniwan Katolik oleh kekuatan hegemoni penguasa negara semenjak Orde Baru.

\section{TINJAUAN PUSTAKA}

Maria Dewi Kristianingrum menulis artikel berjudul "Konstruksi Sosok Perjuangan Mgr. Albertus Soegijapranata, S.J. dalam Film Soegija" di Jurnal THE MESEENGER. 2013. Volume V, No. 2 : 4146. Artikel ini membahas tentang film Soegija dalam analisis framing media. Hasil kajiannya menunjukkan bahwa film Soegija sebagai sarana komunikasi media massa tidak dapat dikatakan netral, karena film Soegija merupakan adaptasi dari catatan harian Mgr. Albertus Soegijapranata, memiliki sedikit banyak perbedaan antara data sejarah dan fakta yang ditampilkan dalam film tersebut.

Ninah Arisyanti menulis dalam Tesis berjudul "Politik Identitas Tokoh Keagamaan Indonesia (KH. Ahmad Dahlan dan Mgr. Soegijapranata) dalam Film Nasional (Analisis Semiotika Media pada Film Sang Pencerah dan Film Soegija”, Program Magister Media dan IImu Komunikasi Universitas Airlangga Surabaya. Tesis yang mengkaji film Sang Pencerah dan Soegija dari kajian Semiotika ini menunjukkan bahwa film tersebut merupakan respons yang tajam dari nilainilai history, cultural, dan political dari sekian banyak tokoh pejuang nasional di Indonesia yang mengalami eksistensi identitas di kalangan tertentu dalam masyarakat Indonesia. K.H. Ahmad Dahlan pada film Sang Pencerah dikostruksikan sebagai tokoh pejuang nasional Indonesia dari tradisi keras Islam abangan saat itu dan beralih kepada syariat Islam sesuai dengan Al-Qur'an dan Al Hadits. Mgr. Albertus Soegijapranata dikonstruksikan sebagai tokoh pejuang nasional Indonesia dalam film Soegija. Adegan saat Romo Soegija melihat warga Belanda yang ditangkap oleh Jepang, termasuk suster dan bruder Belanda dibawa ke interniran, tampak Romo Soegija tidak bisa berbuat apapun kecuali menyelamatkan gereja dari rencana Jepang menjadikan gereja sebagai markas komando. Kedua film biopik tersebut mengkonstruksikan bagaimana nilai-nilai kemanusiaan seorang tokoh agama harus melakukan upayaupaya yang tegas demi kepentingan masyarakat di negaranya.

Sandy Allifiansyah mempublikasikan artikel berjudul "Oposisi Biner Kesejarahan Indonesia Periode Revolusi Fisik (19451949) dalam Film Soegija (2012) dan Sang Kiai (2013)." Semiotika: Jurnal Komunikasi, Vol. 11, No. 1 (2017), hlm, 163-200. Artikel ini mengkaji teks film sebagai teks fiksi dengan memposisikan cara berpikir oposisi 
biner terhadap teks kesejarahan di dalam media sinema. Historiografi visual yang disajikan dalam kedua film biopik ini (Soegija dan Sang Kiai) menunjukkan kesamaan narasi. Kesamaan narasi yang ditampilkan melalui imajinasi historis dari kemunculan tokoh-tokoh rekaan yang dimaknai secara simbolis.

Dwi Haryanto dalam artikel yang berjudul "Biopic Film and Political Identity: Contestation of Diversity of Ideology in Indonesia Movies text Post-Soeharto Regime" Capture: Jurnal Seni Media Rekam, Vol. 10. No. 1 Desember 2018, hlm, 46-64, mengkaji film-film biopik Gie, Soegija, Sang Kiai, Soekarno, dan Jenderal Soedirman. Hasil kajiannya tampak keragaman atas eksistensi politik identitas dari perspektif agama, etnis, ataupun platform ideologi politik dalam film-film biopic tersebut. Film-film tersebut juga menjadi penanda hadirnya semangat dan kesadaran ethnic nasionalism ataupun civic nasionalism. Tokoh-tokoh yang dihadirkan dalam film biopik merupakan tokoh-tokoh dengan keragaman identitas, namun disatukan oleh satu konsepsi wacana keIndonesia-an sebagai ideologi dan identitas kolektif. Film biopik pasca rezim Orde Baru memunculkan keragaman ideologi dan politik identitas dari keterwakilan tokohtokoh Soe Hok Gie, Mgr. Albertus Soegijapranata, K.H. Hasyim Asy"ari, Soekarno, dan Jenderal Soedirman sebagai subject matter. Selain itu, menjadi

alternatif bagi historiografi sejarah perfilman Indonesia, terutama setelah tumbangnya Rezim Orde Baru.

Kajian artikel ilmiah ini berbeda dengan kajian-kajian terdahulu, karena kajian ini mengkaji tujuan utama dari film dengan konten teks sejarah biografi dari Mgr. Albertus Soegijapranata yang dipindahkan ke medium film layar lebar. Permasalahan penelitian ini adalah relevansi tujuan produksi film Soegija terhadap historiografi Indonesia bertujuan menggali sejauhmana posisi film tersebut dalam konteks teks narasi historiografi Indonesia yang selama ini mengalienasikan peran dari tokoh-tokoh agama dari golongan minoritas dalam sejarah revolusi kemerdekaan Indonesia. Permasalahan lain yang ingin digali adalah faktor-faktor kepentingan dalam produksi film Soegija yang menjadi sangat penting untuk menegaskan posisinya sebagai bagian dari eksistensi politik identitas terhadap historiografi Indonesia.

\section{METODE}

$\begin{array}{lrr}\text { Kajian } & \text { menggunakan } & \text { Pendekatan } \\ \text { Dekonstruksi } & \text { Derrida } & \text { yang } \\ \text { mengedepankan } \quad \text { Paradigma } & \text { Post- } \\ \text { Positivism. Pemikiran Dekonstruksi Derrida } \\ \text { berupaya untuk menunjukkan bahwa ada } \\ \text { pemikiran lain yang bisa menjadi pemikiran } \\ \text { alternatif di samping pemikiran yang telah } \\ \text { "ada". Konsep yang ditawarkan ini bisa } \\ \text { menjadi suara lebih bagi pemikiran- } \\ \text { pemikiran yang selama ini terpinggirkan }\end{array}$


oleh pemikiran tunggal. Dekonstruksi tidak berarti menjurus pada penghancuran suatu konsep tanpa solusi, tapi bisa menawarkan konsep baru untuk menggantikan konsep lama. Kelebihan dari Dekonstruksi ini bisa memacu para pemikir lain untuk ikut andil dalam menentukan kebenaran menurut apa yang mereka butuhkan (Nurhidayat, 2015). McQuillan menyatakan ada lima strategi untuk memahami Dekonstruksi. Salah satunya adalah bagaimana Dekonstruksi dipahami sebagai kontaminasi oposisi-oposisi biner, pasangan makna yang berlawanan, misalnya oposisi biner itu seperti rasional dan irasional, maskulin, dan feminisme, fiksi dan realitas. Dekonstruksi fokus pada yang terpinggir atau termarjinalkan, misalnya dalam oposisi biner, pria dan wanita, rasional dan emosional, progresif dan terbelakang. Dalam konteks ini istilah di pinggiran, wanita, emosional, dan terbelakang adalah yang termarjinal. Dengan adanya oposisi biner ini, maka tidak ada hegemoni makna dari salah satu kutub dan kedua kutub menjadi sama kuat (dalam Hardiman, 2015). Menurut pandangan Post-Posivitism, kebenaran tidak hanya satu tetapi lebih kompleks, sehingga tidak dapat diikat oleh satu teori tertentu saja (Rahmat, 2009).

Kajian film Soegija ini menggunakan Pendekatan Kualitatif yang terdiri atas serangkaian praktik material, interpretif deskritif, representasi, meliputi data berupa kata-kata (kutipan berasal dari wawancara, catatan lapangan, percakapan), potongan gambar (capture image), foto, rekaman, ataupun bahan empiris seperti teks sejarah, studi kasus, pengamatan interaksional dan visual, dokumen pribadi dan dokumen resmi, dan bukan angka (N. K. Denzin \& Lincoln, 1994 ; N. K. Denzin \& Lincoln, 2011; Upe \& Damsid, 2010 ; Rahmat, 2009).

Pengumpulan data menggunakan metode Wawancara, sedangkan terkait dengan konten cerita sejarah dalam film ditunjang dengan metode Studi Pustaka berupa telaah teks historiografi. Hal ini berhubungan dengan kajian film sejarah bahwa metode Studi Pustaka berdasar pada kerangka teori Heuristik dan kritik internal yang secara umum merupakan prosedur dalam penelitian sejarah. Menurut (Sjamsuddin, 2016) "Heuristik (heuristic) sebuah kegiatan mencari sumber-sumber untuk mendapatkan data-data, atau materi sejarah, atau evidensi sejarah." Teori Heuristik menerapkan metode tentang teknik atau cara-cara untuk menemukan sumber yang bisa diperoleh melalui studi kepustakaan, pengamatan secara langsung di lapangan (jika memungkinkan), melalui interview untuk sejarah kontemporer. Sumber sejarah sebagai data dapat diperoleh dari kronik, annual, biografi, geneologi, memoir, catatan harian, sejumlah inskripsi tertentu, karya seni yang meliputi potret, lukisan-lukisan sejarah, 
patung, sejumlah film tertentu, kineskop, dan lain-lain (Sjamsuddin, 2016). Oleh karena itu, operasionalisasi teknik pengumpulan data dalam penelitian kajian ini terkait dengan metode Studi Pustaka, dilakukan dengan menemukan data-data berdasarkan fakta sejarah dengan menelusuri sumber-sumber referensi, baik primer maupun sekunder dari buku-buku sejarah (historiografi), jurnal ilmiah, makalah, maupun berita di surat kabar yang membahas tentang teks naratif histori biografi. Data-data tersebut untuk membuktikan keterkaitan konten film dengan historiografi Indonesia. Untuk itu, dilakukan kritik internal sebagai bagian dari kritik sumber juga dilakukan terkait dengan teknik pengumpulan data. Kritik sumber dengan melakukan kritik internal untuk memperoleh kebenaran atau ketepatan (akurasi) dari sumber sejarah (Sjamsuddin, 2016). Hal ini merupakan bagian dari tahapan kegiatan verifikasi atau pengujian terhadap sumber-sumber sejarah pada data teks historiografi untuk mendukung bahasan kajian alih wahana (adaptasi) pada film biopik yang dikaji. Film biopik merupakan film epik sejarah yang harus berdasar pada fakta-fakta sejarah. Tugas kritik internal untuk menegakkan akurasi terhadap fakta-fakta sejarah (Sjamsuddin, 2016).

Pengumpulan data wawancara terhadap nara sumber dilakukan dengan metode Wawancara Mendalam agar lebih akurat. Adapun informan atau narasumber yang terdiri atas sutradara, produser, dan pengamat film. Analisis data dilakukan dengan Analisis Interaksi berdasar pada data kualitatif. Data diperoleh melalui wawancara secara langsung maupun dari penelusuran sumber data secara heuristik terhadap filmmaker yang terdiri atas sutradara dan produser dari film biopik Soegija.

\section{PEMBAHASAN}

\subsection{Afirmasi Politik: Relevansi Tujuan Produksi Film Soegija terhadap Teks Historiografi Indonesia}

Produksi film biopik yang menghadirkan sejarah biografi dari tokohtokoh popular oleh para filmmaker jelas memiliki tujuan yang bersifat idealis. Menurut Marseli Sumarno, pakar film Fakultas Film dan Televisi, Institut Kesenian Jakarta (FFTV-IKJ) bahwa:

"Film sebagai karya seni mengandung pesan-pesan yang ingin disampaikan kepada publik melalui yang disebut director statement. Director statement merupakan tujuan dari pesan yang ingin dicapai dari film yang diproduksi. Tujuan dari pesan ini mengandung pemaknaan sebagai ide atau gagasan awal atas film yang akan diproduksi" (Wawancara Marseli Sumarno, 8 Mei 2017).

Film biopik sebagai film dokudrama sejarah memiliki sudut pandang terhadap subyek atau karakter tokoh yang dihadirkan dalam media film sebagai produk tontonan. Sudut pandang pembuatnya dapat 


\section{CAPTURE}

mengindikasikan makna-makna dari pesanpesan apa yang ingin disampaikan kepada penonton dalam film yang diproduksinya sebagai tujuan idealisme atas produk film. Dengan demikian, akan terlihat tujuan dari para filmmaker terhadap produksi filmnya tersebut.

Tujuan utama dari produksi film Soegija secara tersirat terlihat dari director statement yang merupakan sudut pandang filmmaker-nya. Garin Nugroho menyatakan:

Tujuan dari film biopik Soegija adalah pertama, menghadirkan tokoh katolik dari kelompok minoritas yang kontribusinya terhadap sejarah berdirinya Negara Indonesia tidak memperoleh pengakuan di dalam historiografi Indonesia. Kedua, menggambarkan proses bagaimana diplomasi politik yang dilakukan oleh Mgr. Albertus Soegijapranata terhadap Tahta Suci Vatikan yang kemudian mengutus Mgr. D'Aroye ke Indonesia dan mengakui kedaulatan RI di bawah SoekarnoHatta. Walaupun peristiwa ini pun tidak disebutkan dalam historiografi kemerdekaan Indonesia (Wawancara Garin Nugroho, 28 Februari 2020).

Film Soegija (representasi biografi Mgr. Albertus Soegijapranata) dapat diartikan sebagai artikulasi dan ekspresi politik identitas (Haryanto, 2018).

Romo I.Y. Iswarahadi selaku eksekutif produser mengatakan tujuan produksi film Soegija tampak dalam penjelasannya berikut:

$$
\text { Monsinyur yang bagi gereja }
$$

maupun bagi dunia luar itu punya peranan penting. Terutama terkait dengan cita-cita kebangsaan, yaitu nilai nasionalisme dari pemimpin umat Katolik. Soegija dan gereja punya andil juga dalam membangun negeri ini melalui sikap kebangsaan yang dicerminkan dari sikap dan pemikiran Mgr. Albertus Soegijapranata, yang walau mewakili kelompok minoritas tetapi memiliki kepercayaan diri untuk melawan penjajah, termasuk diplomasi politik dengan Tahta Suci Vatikan untuk mengakui kedaulatan Indonesia dari kolonialis Belanda. Bagian penting dari pembuatan film ini adalah karena kiprah dari Monsinyur ini tidak diakui dalam historiografi Indonesia. Film ini hadir untuk menunjukkan kepada masyarakat tentang nilai-nilai semangat kebangsaan ini hanya akan tercapai dan bisa dipupuk kalau tiap orang tidak hanya mementingkan agamanya sendiri atau kelompoknya sendiri (Wawancara Romo I.Y. Iswarahadi, 9 Mei 2016).

Penjelasan Romo I.Y. Iswarahadi tampak bahwa tujuan film Soegija adalah menunjukkan nilai-nilai semangat kebangsaan hanya akan tercapai dan bisa dipupuk, jika setiap orang tidak hanya mementingkan agamanya sendiri atau kelompoknya sendiri. Penegasan dari tujuan produksi film Soegija selaras dengan adegan dan konten film.

Adegan diplomasi politik yang dilakukan oleh Mgr. Albertus Soegijapranata kepada Tahta Suci Vatikan tampak ada film ini. Sebagai wujud dukungan politik, Tahta Suci Vatikan 
mengutus Mgr. George de Jonge d'Ardoye menjadi Duta Tahta Suci Vatikan yang mendukung pemerintahan Soekarno dan Hatta. Mgr. George de Jonge d'Ardoye dengan Mgr. Albertus Soegijapranata kemudian menemui Soekarno di Gedung Agung Yogyakarta untuk menyatakan bahwa Negara Vatikan secara resmi mendukung kemerdekaan Indonesia. Hal itu menunjukkan bahwa meskipun film Soegija dalah film fiksi, tetapi tetap mendasarkan pada kebenaran sejarah (historical truth), sebagaimana konsep yang dikemukakan oleh sejarawan (Kuntowijoyo, 2006) bahwa karya fiksi sejarah yang sengaja menggunakan peristiwa sejarah sebagai bahan, haruslah mempunyai ikatan kepada historical truth (kebenaran sejarah). Film biopik sebagai film fiksi sejarah tidak dapat mengabaikan ataupun melepaskan diri dari keberadaan fakta-fakta sejarah dari subjek atau tokoh yang diangkat. Fakta sejarah masa lalu direkonstruksi peristiwanya pada penuturan cerita dengan mempertimbangkan logika dari kronologi peristiwa, kemudian diadaptasi ke dalam medium film.

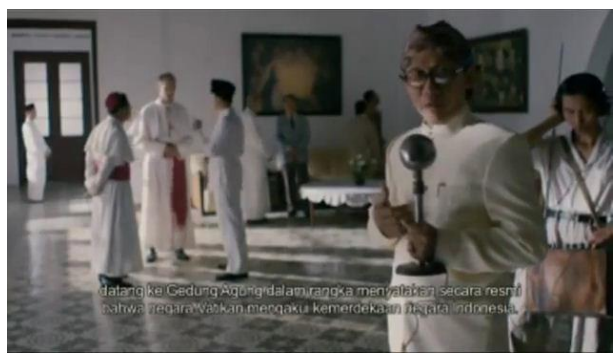

Gambar 1. Adegan Pak Besut melalui siaran radio memberitakan perihal Kedatangan Monsinyur George de Jonge d'Ardoye Utusan Tahta Suci Vatikan menemui Presiden Soekarno di Gedung Agung
Yogyakarta untuk mendukung kedaulatan dan kemerdekaan Indonesia. Kedatangan Monsinyur George de Jonge d'Ardoye merupakan keberhasilan diplomasi politik yang diakukan oleh Mgr Albertus Soegijapranata. (Sumber: Soegija, 2012, TC: 00:58:39-00:59:31).

Salah satu adegan dalam film itu menggambarkan Romo Soegija melakukan diplomasi dengan Negara Vatikan yang diwakili oleh Monsinyur George de Jonge d'Ardoye untuk mendukung kedaulatan Indonesia. Sekuen adegan film ditunjukkan dengan siaran radio oleh Pak Besut yang memberitakan tentang upaya Uskup Mgr. Albertus Soegijapranata mengantar wakil dari Negara Vatikan Monsinyur George de Jonge d'Ardoye bertemu dengan Bung Karno. Monsinyur George de Jonge d'Ardoye secara resmi menyatakan bahwa Negara Vatikan mendukung kemerdekaan Indonesia. Pernyataan dukungan politik tersebut disampaikan pada saat bertemu dengan Bung Karno di Gedung Agung. Hal ini merupakan hasil diplomasi Mgr. Albertus Soegijapranata. Adegan menampilkan Mgr d'Ardoye, Romo Soegija, dan Bung Karno sedang melihat-lihat lukisan koleksi Bung Karno karya dari seniman istana seperti Basuki Adullah, Affandi, dan juga Soedjojono.

Fakta sejarah yang bersumber dari beberapa teks historiografi yang ditulis di kalangan internal umat Katolik menuliskan bahwa Romo Soegija mengirim surat ke Vatikan. Surat berisi permohonan agar Vatikan sebagai negara berdaulat mendukung kedaulatan pemerintah Republik Indonesia yang dipimpin oleh 
Soekarno-Mohammad Hatta. Tujuannya untuk memperkuat posisi $\mathrm{Rl}$ dalam perundingan dengan Belanda. Vatikan pun merespon surat Romo Soegija dengan menyetujui permohonan tersebut dan selanjutnya mengangkat Monsinyur George de Jonge d'Ardoye sebagai Delegat Apostolik untuk Indonesia. Pada tanggal 30 Desember 1947 pada pukul 12.00 WIB dengan ditemani oleh Romo Soegija, Mgr. d'Ardoye menemui Wakil Perdana Menteri untuk menyerahkan Surat (Kepercayaan) dari Sekretariat Vatikan. Pada pukul 12:30 WIB dari Wakil Perdana Menteri menuju ke Istana Gedung Agung untuk bertemu dengan Presiden Soekarno. Utusan Vatikan Mgr. d'Ardoye bertemu dengan Presiden Sukarno dalam sebuah perjamuan yang hangat (Subanar, 2012 ; Sudimin \& Gunawan, 2015; Utami, 2012 ; Wijayanto, 2012). Fakta sejarah tersebut menunjukkan dukungan pengakuan Vatikan terhadap kedaulatan Republik Indonesia yang dimulai dengan kunjungan delegasi Takhta Suci Vatikan beberapa kali tahun 1947-1948 dan akhirnya Indonesia menempatkan Wirjopranoto sebagai Duta Besar di Vatikan pada tahun 1950.

Pengakuan kedaulatan Indonesia oleh Vatikan tidak dapat dilepaskan dari peran Romo Soegija. Berkat inisiatif dari Romo Soegija melakukan lobi-lobi politik, maka terjalinlah hubungan diplomatik antara pemerintah Indonesia dengan
Vatikan. Hubungan yang sekaligus merupakan wujud pengakuan Vatikan atas kemerdekaan Republik Indonesia. Pengakuan Vatikan atas kemerdekaan Indonesia tentu saja memiliki nilai yang sangat strategis dalam kancah hubungan internasional.

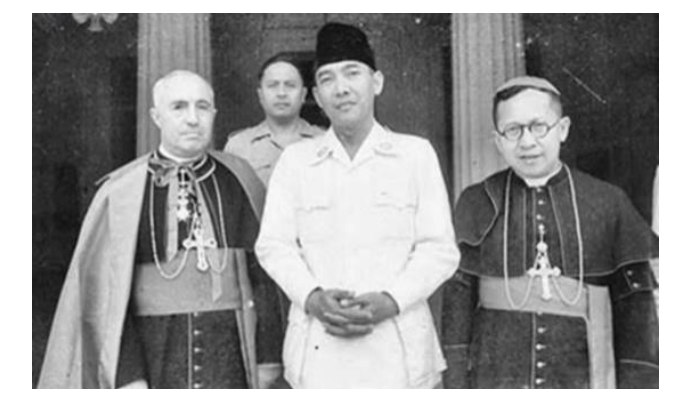

Gambar 2. Mgr. Georges de Jonghe d'Ardoye (kiri) bertemu Presiden Soekarno (tengah) di Yogyakarta, didampingi Mgr. Albertus Soegijapranata (kanan) (Sumber: perpusnas-Ipphos).

Fakta sejarah bersumber dari beberapa teks historiografi di kalangan internal umat Katolik menuliskan upaya Romo Soegija meminta pengakuan kedaulatan dan dukungan terhadap pemerintahan Repulik Indonesia yang dipimpin oleh Soekarno-Hatta kepada Vatikan hingga pengangkatan Mgr. d'Ardoye sebagai Apostolik Indonesia menunjukkan adanya relevansi tekstual antara teks histriografi dengan teks visual dalam cerita film. Sekuen adegan tersebut, dalam perspektif kajian adaptasi (alih wahana) merupakan transposisi dari medium teks narasi sejarah historiografi ke medium audiovisual film. Berdasarkan data teks visual dan teks naratif pada layar film serta data teks historiografi menunjukkan terjadinya afirmasi politik tentang peran 
Mgr. Albertus Soegijapranata melalui tindakan diplomasi politik, yang selama ini termarginalkan bahkan teralienasikan dalam historiografi Indonesia.

Film Soegija dengan tegas menunjukkan kepada publik bahwa gereja dan pimpinan umat Katolik turut berkonstribusi terhadap peristiwa-peristiwa besar sejarah kemerdekaan Indonesia. Bahkan, sejarah diplomasi politik yang dilakukan oleh Romo Soegija begitu besar dampaknya terhadap melemahnya eksistensi kolonialisme Belanda. Berdasarkan risetnya, Garin Nugroho menjelaskan:

"Memang betul bahwa ketika Vatikan mengirim delegasi ke sini kurang diakui dalam historiografi Indonesia. Padahal, pengaruhnya Vatikan demikian besar di negaranegara Katolik. Minimal mereka tidak bersikap keras dengan Tahta Suci Vatikan mengutus utusan ke Indonesia. Maka dari itu, Mgr. D'Aroye itu ada dalam adegan film Soegija. Di internal negara Belanda sendiri, partai Katolik di Belanda juga pasti men-support. Fakta-fakta ini yang jarang sekali muncul di historiografi Indonesia. Bahkan hampir tidak ada" (Wawancara Garin Nugroho, 28 Februari 2020).

Analisis data sekuen adegan film dapat disimpulkan adanya hubungan rekonstruksi referensial. Konten cerita film mengacu pada rekonstruksi atas referensi sejarah yang menegaskan tujuan diproduksinya film Soegija sebagai wujud dari afirmasi politik terkait kontribusi sejarah Romo Mgr. Albertus
Soegijapranata semasa revolusi kemerdekaan Indonesia. Kontribusi sejarah politik pimpinan dari kelompok minoritas Katolik kepada bangsa dan negara. Afirmasi politik yang menegaskan terhadap penulisan sejarah (historiografi) Indonesia sebagai hasil dari penelaahan secara dekonstruksi. Bagaimana film Soegija merupakan perlawanan kultural edukatif yang menempatkan tokoh dari golongan minoritas beroposisi biner dengan tokohtokoh sipil nasionalis ataupun militer dalam konstruksi narasi historiografi Indonesia oleh negara semasa revolusi kemerdekaan. Rekonstruksi peristiwa yang melibatkan tokoh Mgr. Albertus Soegijapranata dan waktu terjadinya peristiwa sejarah berupa adegan Mgr. Albertus Soegijapranata meminta Vatikan untuk mendukung kedaulatan dan kemerdekaan Indonesia hingga akhirnya Vatikan mengangkat Mgr. d'Ardoye sebagai Vikaris Apostolik Indonesia mengacu pada kebenaran fakta sejarah berdasar referensi teks historiografi (historical truth). Referensi sejarah sebagai sumber sineas untuk melakukan rekonstruksi adegan di layar film. Dengan demikian, film Soegija sebagai bentuk reaksi politik dan afirmasi sejarah atas diri Romo Soegija, tokoh dari golongan minoritas Katolik yang kiprah perjuangan diplomasinya kurang memperoleh pengakuan secara tegas dalam historiografi Indonesia semasa kekuasaan 
rezim Orde Baru, khususnya terkait dengan sejarah diplomasi politik semasa awal-awal pengakuan terhadap kemerdekaan Indonesia.

\subsection{Faktor-Faktor Kepentingan Produksi Film Soegija: Politik Identitas Film Soegija atas Historiografi Indonesia}

Produksi film, selain didasari oleh kebutuhan komersial, juga berfungsi sebagai media massa di ruang publik. Film mampu memediasi dan mengartikulasikan kepentingan-kepentingan sosial, politik, sejarah, agama, ataupun kebudayaan, khususnya di Indonesia yang sangat heterogen, pluralis, dan multukultural. Para filmmaker berani menyuarakan kebebasan berekspresinya dengan mengeksplorasi tema-tema politik. Beberapa film menyajikan latar belakang situasional tahun 1965, seperti film Surat Dari Praha (2016, Angga Dwimas Sasongko), Istirahatlah Kata-Kata (2017, Yosep Anggi Noen), Student Movement in Indonesia (2002, Tino Saroengallo), 9808, Antologi 10 Tahun Reformasi (2008, Edwin, Ifa Isfansyah, Lucky Kuswandi, dan Ucu Agustin), May (2008, Viva Westi), dan Di Balik 1998 (2015, Lukman Sardi). Ada juga film-film yang mengeksplorasi persoalan agama sebagai ideologi ataupun identitas, seperti “?" (Tanda Tanya) (2011, Hanung Bramantyo) dan Perempuan Berkalung Sorban (2009, Hanung Bramantyo). Filmfilm tentang identitas etnis Tionghoa yang mengalami subordinasi secara identitas, politik, dan kebudayaan juga tampak pada film GIE (2004, Riri Riza) dan Merry Riana: Mimpi Sejuta Dolar (2014, Hestu Saputra).

Beberapa waktu lalu publik diramaikan dengan kehadiran film dokumenter Jagal (2012) dan Senyap (2014) karya Josua Oppenheimer yang menimbulkan kegaduhan karena adanya penolakan dari masyarakat ataupun organisasi massa yang berujung pada pelarangan pemutaran film tersebut. Filmfilm tersebut merupakan film-film yang mendekonstruksi film-film mainstream yang memang diproduksi untuk kepentingan orientasi komersial di industri film Indonesia. Setidaknya film-film tersebut merupakan film yang berani untuk tidak menitikberatkan sisi komersial, karena lebih mengutamakan idealisme konten cerita. Film tersebut bukan dikategorikan eksploitasi film yang laku dan disukai penonton Indonesia, seperti film yang mengumbar unsur seksualitas, horor, kekerasan, ataupun komedi. Film-film Surat Dari Praha, Istirahtlah Kata-Kata, Student Movement in Indonesia, 9808, Antologi 10 Tahun Reformasi, May, Di Balik 1998, “?” (Tanda Tanya), Perempuan Berkalung Sorban, GIE, Merry Riana: Mimpi Sejuta Dolar, Jagal, dan Senyap merupakan film yang beroposisi biner dengan menghadirkan keberpihakan kepada pihakpihak termarjinalkan dalam konstruksi sejarah.

$$
\text { Deskripsi di atas menunjukkan }
$$


bahwa selain motif komersial, film-film Indonesia juga mengidentifikasi motif-motif eksistensi identitas, khususnya film-film bertema agama, contohnya film Ayat-Ayat Cinta, Perempuan Berkalung Sorban, Ketika Cinta Bertasbih, Sang Pencerah, Sang Kiai, dan "?" (Tanda Tanya). Demikian juga film Soegija. Meskipun dalam sejarah industri perfilman yang mengangkat isu-isu identitas dan agama juga seringkali meninggalkan kontroversi dan polemik di tengah masyarakat, seperti film "?" (Tanda Tanya) yang dianggap mendiskreditkan dan menstereotipe umat Islam oleh MUI (Majelis Ulama Indonesia). MUI beralasan dalam film tersebut umat Islam digambarkan berperilaku kasar, penuh dengan sikap picik dan kebodohan, intoleran, eksklusif, rasis, dan brutal ataupun anarkis, sedangkan umat Katolik dan etnis Cina digambarkan sangat toleran, penuh kesabaran, kesantunan, pengertian, penuh kasih dan sering digambarkan menjadi korban kekerasan umat Islam. Bahkan, di awal-awal film ditampilkan adegan penusukan seorang pastur yang akan memimpin misa di gereja oleh orang Islam (Salim, 2011).

Isu-isu poligami di kalangan dunia pesantren tampak dalam film Perempuan Berkalung Sorban. Film drama bertema Islam yang diadaptasi dari novel dengan judul yang sama, memang menyajikan latar tradisi sekolah pesantren di Jawa Timur. Tradisi yang cenderung mempraktikkan tradisi konservatif terhadap wanita dan kehidupan modern. Film tersebut menceritakan kehidupan pesantren Salafiah Putri Al-Huda yang mengajarkan bagaimana seorang perempuan harus patuh dan tunduk kepada laki-laki, terlebih lagi kepada suaminya. Ajaran tersebut membuat Anissa beranggapan bahwa ajaran Islam hanya membela kaum lakilaki. Ajaran yang menempatkan perempuan dalam posisi sangat lemah di hadapan kaum laki-laki. Persoalan identitas dan agama rupanya sangat penting dalam industri perfilman di Indonesia. Hal ini disebabkan, isu-isu identitas, apalagi identitas agama merupakan potensi untuk dikemas menjadi komoditas jualan berupa komoditas film.

Konten cerita film biopik Indonesia juga memunculkan isu-isu terkait eksistensi identitas, khususnya yang mengangkat tentang tokoh-tokoh agama. Akan tetapi, identitas pada film-film biopik bersifat positif, karena terkait dengan eksistensi identitas yang melekat pada tokoh yang difilmkan dan berkonstribusi terhadap nilainilai moralitas dan kepribadian personal terhadap sikap kebangsaan dan keberterimaan atas heterogenitas, pluralitas, dan multikultural yang menjadi ciri masyarakat di Indonesia. Bagaimana pun persoalan agama di Indonesia merupakan bagian inheren dari identitas pribadi maupun komunal secara sosiologis. Di Indonesia terdapat ikatan-ikatan sosial 
yang berbasis pada identitas menonjolkan peran militer dan sipil primordialisme, termasuk di antaranya adalah berbasis pada agama. Salah satu dari tiga pendekatan pembentuk identitas adalah primordialisme. Identitas diperoleh secara alamiah turun temurun, seperti etnis, ras, agama (Widayanti, 2009). Film Soegija dalam konten ceritanya sangat melekat dengan eksistensi identitas tokoh agama Katolik yaitu Mgr. Albertus Soegijapranata. Oleh karena itu, perlu pembahasan bagaimana faktor-faktor yang mempengaruhi kepentingan produksi film Soegija dalam posisinya terhadap historiografi Indonesia sebagai telaah kritis berbasis pada media film.

Medium film sebagai alat aktualisasi politik identitas memiliki relevansi yang positif bagi kepentingan politik golongan minoritas. Produksi film pasti dilatarbelakangi oleh kepentingankepentingan tertentu. Demikian pula produksi film Soegija yang lekat dengan identitas pimpinan umat Katolik. Film Soegija bisa diartikan sebagai aktualisasi dan ekspresi politik golongan minoritas, khususnya terkait dengan posisi dalam historiografi Indonesia. Film Soegija beroposisi biner dalam perspektif dekonstruksi Derrida. Premis ini terlihat dari bagaimana selama ini kiprah dan peran dari Mgr. Abertus Soegijapranata teralineasikan dalam narasi besar historiogafi kemerdekaan Indonesia, terutama semasa Orde Baru yang lebih nasionalis dibandingkan golongan tokohtokoh agama. Film Soegija dapat dikatakan merupakan bagian dari ekspresi politik identitas merujuk pada definisi politik identitas yang dikemukakan oleh Maarif (dalam Fauzi dan Panggabean, 2012) yang menyatakan "suatu praktik politik yang dikaitkan dengan kepentingan anggotaanggota sebuah kelompok sosial yang merasa diperas dan tersingkir oleh dominasi arus besar dalam sebuah bangsa atau negara". Di situlah letak pemikiran kritis terkait dengan latar belakang produksi film Soegija sebagai artikulasi atas politik identitas melalui telaah Dekonstruksi Derrida. Film Soegija menjadi antitesis terhadap posisi historiografi Indonesia yang lekat dengan identitas militer ataupun sipil nasionalis bahkan film-film yang menghadirkan ulama-ulama Islam.

Produksi film biopik Soegija tidak dapat dihindarkan dari pengaruh atas eksistensi identitas, karena film biopik tersebut dalam perspektif industri perfilman dapat dimaknai sebagai bentuk dari reproduksi identitas. Film biopik Soegija memproduksi teks terkait dengan komoditas identitas yang menjadi strategi jualannya kepada penonton dan sebagai bagian strategis terhadap dekonstruksi historiografi Indonesia. Eksplorasi atas identitas tokoh dan agama yang melekat pada diri karakter utama film, tokoh Mgr. Albertus Soegijapranata berhubungan 
secara marketability dan playability dengan penonton dari kalangan umat Katolik. Bagaimana labeling identitas pengikut umat Katolik jelas merupakan segmentasi dari marketplace film biopik Soegija sebagai komoditas tontonan, sedangkan makna tersembunyi yang sengaja dihadirkan mengarah kepada upaya mendekonstruksi atas historiografi Indonesia semasa revolusi kemerdekaan yang identik dengan identitas kaum militer dan nasionalis sipil, seperti peran terpusat dari tokoh Soekarno, Moh. Hatta, Sjahrir, Tan Malaka, Jenderal Soedirman, maupun Jenderal Soeharto, ataupun tokoh-tokoh dari kalangan agama Islam seperti film Tjoet Nya Dien, Pangeran Diponegoro, Fatahillah, Sultan Agung, dan Sang Kiai.

Garin Nugroho mengemukakan tentang ketokohan dalam film Soegija, bahwa:

Film Soegija merupakan film yang mengangkat tokoh agama katolik yang merupakan uskup pribumi pertama. Tokoh dari yang diidentifikasi dan digolongkan dari kelompok minoritas di Indonesia, yaitu tokoh dengan identitas agama Katolik" (Wawancara Garin Nugroho, 28 Februari 2020).

Penjelasan tersebut selaras dengan pendapat Garin Nugroho dalam artikel media massa bahwa plot film Soegija bercerita tentang kiprah perjuangan dan semangat kepahlawan seorang uskup gereja Katolik bernama Soegijapranata yang lahir di Surakarta, 25 November 1896 yang menjadi Uskup Agung di Keuskupan
Agung Semarang" (Wardhani, 2011). Identitas keagamaan melekat pada diri tokoh Mgr. Albertus Soegijapranata dalam kaitannya dengan perjuangan dan kiprah dari tokoh gereja dalam konteks sebagai sosok pejuang pada masa revolusi kemerdekaan. Faktor memunculkan kekuatan identitas dari tokoh Mgr. Albertus Soegijapranata menjadi kekuatan utama dari film Soegija. Tujuannya jelas, agar ada satu ikatan kolektif dari umat Katolik bahwa mereka berkonstribusi besar dalam revolusi kemerdekaan, seperti juga tokoh agama Islam yang mayoritas, ataupun kalangan sipil nasionalis dan militer. Penggugahan kesadaran kolektif sebagai bagian dari politik identitas tersebut melalui peran positif tokoh agama Katolik pada sejarah berdirinya Republik Indonesia.

Garin Nugroho menunjukkan bahwa produksi film Soegija dilatarbelakangi oleh tujuan tentang kesadaran kebangsaan atau nasionalisme dari tokoh Katolik, seperti Monsinyur Albertus Soegijapranata. Tokoh Katolik juga berkonstribusi terhadap kesadaran kebangsaan pada masa itu. Kesadaran kebangsaan yang dibangun atas pluralitas dan kebhinekaan yang ditunjukkan oleh Romo Soegija perlu untuk dilestarikan. Oleh karena itu, melihat kepentingan itu film Soegija pun diproduksi.

Penokohan Romo Soegija sebagai wujud dari eksistensi identitas dari umat Katolik yang diangkat dalam layar lebar juga dikemukakan oleh Romo Y.I. 
Iswarahadi selaku produser eksekutif film Soegija, yang mengatakan:

Selain tahu tentang siapa Romo Soegija juga menunjukkan bahwa ternyata gereja punya andil juga dalam membangun negeri ini. Dan, umat katolik semakin sadar bahwa meskipun minoritas telah berkontribusi bagi berdirinya Republik ini." (Wawancara Romo Y.I. Iswarahadi, 9 Mei 2016).

Konten film Soegija dengan kiprah dari karakter utama Mgr. Albertus Soegijapranata sebagai pemimpin umat Katolik dengan sangat jelas menunjukkan eksistensi identitas dari umat dan agama Katolik dalam sejarah berdirinya Republik Indonesia. Film Soegija sengaja diciptakan untuk menggerakkan kehidupan bersama untuk meraih cita-cita bangsa berdasar pada semangat nasionalisme, nilai-nilai kemanusiaan, dan multikulural di tengah kebhinekaan kehidupan bangsa Indonesia. Sikap yang dimiliki oleh Mgr. Albertus Soegijapranata pada masa lalu sebagai seorang pemimpin.

Film biopik yang diproduksi oleh filmmaker pasca rezim Orde Baru memang memiliki perspektif baru dengan menghadirkan tema-tema yang non mainstream (non selera pasar) di industri perfilman Indonesia. Para sineas lebih kritis dalam melihat persoalan untuk diartikulasikan dalam medium film dengan memproduksi film biopik sebagai reproduksi identitas dari artikulasi artistik atas realitas politik yang mengalami krisis keteladanan dari elite tokoh-tokoh pemimpin. Reproduksi identitas ini lebih kepada mereproduksi identitas dari tokohtokoh yang memiliki sikap politik yang jelas berkhitmad untuk kepentingan bangsa dan negara, bukan para elite tokoh yang mementingkan diri dan golongannya saja. Tokoh-tokoh dengan identitas agama justru menjadi idola atau panutan yang perlu diteladani karena mampu bersikap dan berkiprah untuk kepentingan bangsa dan negara di atas kepentingan yang berbasis pada primordialisme maupun ikatan emosional religiusitasnya.

Tokoh Mgr. Albertus Soegijapranata meninggalkan identitas agama untuk kepentingan bangsa dan negara tanpa memandang identitas pribadi. Mgr. Albertus Soegijapranata melakukan diplomasi politik kepada pihak Tahta Suci Vatikan untuk mengakui kedaulatan Indonesia serta menjadikan gereja sebagai tempat perlindungan dan pelayanan bagi pengungsi tanpa memandang mereka orang Katolik atau bukan. Semua dilakukannya atas nama kemanusiaan. Semua dilakukan demi kemerdekaan dan pembebasan seluruh rakyat Indonesia dari kekuasaan kolonialisme. Eksistensi identitas dari tokoh tersebut untuk kepentingan bangsa dan negara merupakan daya tarik dari komoditas film biopik Soegija.

Klaim sejarah berdasarkan atas klaim identitas yang melekat pada tokohtokoh yang diangkat dalam film juga 
dikemukakan oleh pengamat film, Moh. Ariansyah mengatakan "faktor identitas dalam konteks produksi film secara strategis berkepentingan dengan sudut pandang akurasi sejarah, kepentingan politik pribadi maupun golongan" (Wawancara Moh. Ariansyah, 8 Mei 2017). Faktor identitas dalam film biopik Soegija berpengaruh terhadap diproduksinya film tersebut. Film tersebut untuk mempertahankan identitas atas sejarah tokoh agama kepada penonton. Begitu pula dengan identitas tokoh tersebut mempertahankan sejarah atas kontribusi tokoh agama Katolik dalam sejarah pergerakan Indonesia berdasarkan konten struktur naratif film. Film biopik Soegija memang secara substansi memiliki relevansi dengan situasional masa pergerakan nasional melawan kolonialisme. Dan, identitas keagamaan sangat kuat pengaruhnya sebagai penanda eksistensi golongan rohaniawan dan agamawan berkontribusi terhadap sejarah revolusi dan pergerakan nasional Indonesia. Dengan demikian, motif eksistensi identitas dalam film biopik Soegija tersebut sangat kuat untuk menegaskan tentang klaim atas fakta sejarah tentang kontribusi tokoh-tokoh agama terhadap bangsa dan negara. Klaim ini merujuk kepada sikap, pemikiran, upaya, dan kegigihan dalam berjuang serta bertahan hidup pada masa Indonesia dikuasai oleh kolonialisme.
Film Soegija merupakan ekspresi dari politik identitas terhadap posisi umat agama minoritas dalam konstruksi historiografi Indonesia yang selama ini memarginalkan tokoh umat Katolik. Wujud dari telaah dekonstruksi atas oposisi biner film Soegija dengan historiografi Indonesia. Hal ini selaras dengan yang dikemukakan oleh (Bagir, 2011) bahwa politik identitas adalah nama untuk menjelaskan situasi yang ditandai dengan kebangkitan kelompok-kelompok identitas sebagai tanggapan untuk represi yang memarjinalkan mereka di masa lalu. Film Soegija dapat dimaknai sebagai kebangkitan dari kesadaran kolektif dari identitas umat Katolik terkait dengan posisi mereka atas historiografi Indonesia. Dekonstruksi atas fakta sejarah tentang eksistensi golongan minoritas terhadap sejarah kebangsaan dan kemerdekaan Indonesia menempatkan film Soegija sebagai antithesis dan upaya meluruskan kebenaran sejarah (historical truth), meskipun melalui medium film fiksi sejarah biografi dari Mgr. Abertus Soegijapranata.

\section{SIMPULAN}

Film biopik Soegija diproduksi bukan tanpa tujuan yang bersifat marketability ataupun playability dalam industri perfilman Indonesia, namun memiliki tujuan politik yang strategis bagi golongan umat Katolik, khususnya terhadap peran gereja dalam historiografi Indonesia semasa revolusi kemerdekaan. Semasa rezim Ore Baru, 


\section{CAPTURE}

sebagian besar historiografi Indonesia memarjinalkan peran-peran golongan agamawan, apalagi dari golongan umat minoritas. Penulisan historiografi yang sudah ada lebih 'mendewakan' peran militer maupun tokoh-tokoh pergerakan dari kalangan sipil nasionalis. Film Soegija menjadi alat perlawanan kultural edukatif dengan melakukan dekonstruksi atas historiografi Indonesia. Film biopik Soegija setidaknya bertujuan untuk memproduksi afirmasi politik bahwa umat Katolik memiliki kontribusi besar terhadap sejarah revolusi kemerdekaan Indonesia. Upaya diplomasi politik Mgr. Albertus Soegijapranata terhadap Tahta Suci Vatikan yang kemudian mendukung kedaulatan RI dengan mengakui Soekarno dan Hatta sebagai pemimpin Negara Republik Indonesia merupakan fakta sejarah. Film ini menjadi afirmasi politik atas fakta sejarah peran strategis dari Mgr. Albertus Soegijapranata sebagai uskup pertama pribumi.

Film Soegija juga merupakan perlawanan secara kultural dan dekonstruksi terkait dengan politik identitas. Produksi film Soegija bertujuan untuk menumbuhkan kesadaran kolektif dari umat Katolik bahwa pimpinan umat Katolik dan gereja memiliki peran strategis semasa revolusi kemerdekaan. Hal itu jarang diketahui oleh publik, termasuk dari kalangan umat Katolik sendiri.

\section{DAFTAR ACUAN}

Pustaka:

Ayawaila, G. R. (2008). Dokumenter: Dari Ide Sampai Produksi. Jakarta: IKJ Press.

Bagir, Z. A. (2011). Pluralisme Kewargaan, Arah Baru Politik Keragaman di Indonesia. Bandung: Mizan dan CRCS.

Denzin, N. K., \& Lincoln, Y. S. (1994). Entering the Field of Qualitative Research. CA: Sage Publication.

Denzin, N. K., \& Lincoln, Y. S. (2011). The Sage Handbook of Qualitative Research 1 ((Terj.)). Yogyakarta: Pustaka Pelajar.

Hardiman, F. B. (2015). Seni Memahami Hermeneuti dari Schleiermacher sampai Derrida. Yogyakarta: Kanisius.

Haryanto, D. (2018). Biopic Film and Political Identity: Contestation of Diversity of Ideology in Indonesian Movies Text Post-Soeharto Regime. CAPTURE: Jurnal Seni Media Rekam, 10(1), 46-64.

Keerigan, F. (2010). Film Marketing. Butterworth-Heinemann: Elsiever Ltd.

Kuntowijoyo. (2006). Budaya dan Masyarakat. Yogyakarta: Tiara Wacana.

Nurhidayat, T. (2015, June 24). Konsep Dekonstruksi Derrida. Retrieved from

https://www.kompasiana.com/amp/ tofix.kompasiana/konsepdekonstruksiderrida_552e12d66ea834b7328b4 570

Palmos, F. (2016). Surabaya 1945 Sakral Tanahku. Jakarta: Yayasan Obor Indonesia.

Pratama, A. F. (2010, May 9). Film Sang Pencerah Hadiah Hanung untuk Muhammadiyah. Retrieved from http://www.tribunnews.com/seleb/2 
010/09/05/film-sang-pencerahhadiah-hanung-untukmuhammadiyah

Rahmat, P. S. (2009). Penelitian Kualitatif. Jurnal EQUILIBRIUM, 5(9), 1-8.

Salim, F. (2011, April 14). Film "?" (Tanda Tanya): Pelecehan Sistematis terhadap Islam. Retrieved from https://www.hidayatullah.com/artike l/opini/read/2011/04/14/47382/filmtanda-tanya-pelecehan-sistematisterhadap-islam.html

Sjamsuddin, H. (2016). Metodologi Sejarah. Yogyakarta: Ombak.

Subanar, G. B. (2012). Soegija Catatan Harian Seorang Pejuang Kemanusiaan. Yogyakarta: Galang Press.

Sudimin, T., \& Gunawan, Y. (2015). Semangat dan Perjuangan Mgr. Albertus Soegijapranata, SJ. Yogyakarta: Kanisius bekerjasama Unika Soegijapranata.

Upe, A., \& Damsid. (2010). Asas-Asas Multiple Researches (dari Norman K. Denzin hingga John W. Creswell dan Penerapannya). Yogyakarta: Tiara Wacana.

Utami, A. (2012). Soegija 100\% Indonesia. Jakarta: Kepustakaan Populer Gramedia bekerjasama dengan Puskat Pictures.

Wardhani, A. K. (2011, April 19). Garin Nugroho Angkat Tokoh Kebhinekaan ke dalam Sinema. Retrieved from http://www.tribunnews.com/seleb/2 011/04/19/garin-nugroho-angkattokoh-kebhinekaan-ke-dalamsinema

Widayanti, T. (2009). Politik Subaltern: Pergulatan Identitas Waria. Yogyakarta: Pusat Penelitian Politik dan Pemerintahan Jurusan Politik dan Pemerintahan UGM.

Wijayanto, FX. M. H. (2012). Soegija in Frames. Jakarta: Kepustakaan Populer Gramedia bekerjasama dengan Puskat Pictures.

\section{Narasumber:}

Garin Nugroho Rianto (55), Sutradara Film Soegija. Alamat: Jl. Rajawali HD 5a No. 1, Bintaro, Sektor 9, Tangerang.

Marselli Sumarno (63), Pakar dan Praktisi Film serta Dosen Fakultas Film Televisi Institut Kesenian Jakarta (IKJ), Kompleks TIM, Jl. Cikini Raya No. 73, RT. 08 / RW. 2, Cikini, Menteng, Jakarta Pusat.

Mohamad Ariansah (45), Pengamat Film dan Dosen Fakultas Film Televisi Institut Kesenian Jakarta (IKJ), Kompleks TIM, JI. Cikini Raya No. 73, RT. 08 / RW. 2, Cikini, Menteng, Jakarta Pusat.

Romo Y.I. Iswarahadi, SJ, (57), Direktur SAV Puskat dan Eksekutif Produser Film Soegija, Alamat: Balai Budaya Sinduharjo Jl. Kaliurang Km. 8,5 Jaban, Sinduharjo, Ngaglik, Sleman Yogyakarta 55581-Indonesia. 